\title{
Tools of Reason: The Practice of Scientific Diagramming from Antiquity to the Present
}

\author{
Greg Priest ${ }^{\mathrm{a}, *}$, Silvia De Toffoli ${ }^{\mathrm{b}}$, Paula Findlen ${ }^{\mathrm{a}}$ \\ ${ }^{a}$ Stanford University, Department of History, United States \\ b Stanford University, Department of Philosophy, United States
}

A R T I C L E I N F O

\author{
Keywords: \\ Diagrams \\ DNA \\ DNA topology \\ Double helix \\ Francis Crick \\ James Watson \\ Knot diagrams \\ Mathematical practice \\ Scientific practice
}

In the fourth volume of the Encyclopédie, ou dictionnaire raisonné des sciences, des métiers et des arts (1751-1772), the French mathematician and philosophe Jean d'Alembert, coeditor of this monument to Enlightenment, offered a pithy definition of the French word diagramme: "It is a figure or a construction of lines intended to explain or demonstrate a proposition. See Figure.” This eighteenth-century understanding of a geometric diagram reflects a long, tangled history of a concept. As d'Alembert observed, "This word is more often used in Latin, diagramma, than in French. One simply uses the word figure." The same volume contained Rousseau's remarks on diagram as a term of art in ancient music to describe "scale, range, or system." ${ }^{1}$ Both definitions invoked a word of great antiquity that performed more than one function.

Diagramming is an iconic expression of the human ability to reduce key concepts to their essential visual expression. Diagrams are pervasive in the discovery, development, and communication of scientific and mathematical ideas and technological systems. They abstract physically complex entities; they outline certain features at the expense of others to focus our attention on specific

\footnotetext{
* Corresponding author.

E-mail address: greg@gregpriest.com (G. Priest).

1 Jean d'Alembert, "Diagramme," in Encyclopédie, ou dictionnaire raisonné des sciences, des métiers et des arts, vol. 4, ed. Denis Diderot and Jean d'Alembert (Paris, 1751-1772), 933. We thank John Bender and Michael Marrinan, The Culture of Diagram (Stanford: Stanford University Press, 2010), 10, for bringing this entry to our attention.
}

operations; they make visible what might otherwise be invisible. In The Life of Sir Isaac Newton (1831) David Brewster spoke admiringly of "a remarkable diagram relative to the solar system" inscribed on scroll adorning Newton's 1731 tomb in Westminster Abbey (Figure 1$)^{2}$ It is telling that at the end of Newton's celebrated life as the most famous mathematical philosopher of his age, a diagram became the essential expression of what he had accomplished with his explanation of celestial motions in his Philosophiæ Naturalis Principia Mathematica (1687).

Scientists and mathematicians diagram a vast array of objects, relationships, and processes. Cosmological images are among the oldest diagrams outlining competing interpretations of the natural world. Many examples survive from the Middle Ages, suggesting their even greater antiquity. A diagram may depict a two-dimensional object-a Euclidean diagram of an equilateral triangle. It can be a two-dimensional projection of a threedimensional object-a fossil or a mathematical knot. It can represent natural processes-the circulation of the blood, the stratification of the earth, the motions of the heavens-of varying scale and complexity. A diagram may also show relationships, such as when a phylogeny depicts the genealogical relationships among different organisms, or when the Swiss linguist Ferdinand de Saussure famously depicted language as a series of parallel

\footnotetext{
${ }^{2}$ David Brewster, The Life of Sir Isaac Newton (London: John Murray, 1831), 324. This is one of many examples of the use of "diagram" in English found in the Oxford English Dictionary.
} 


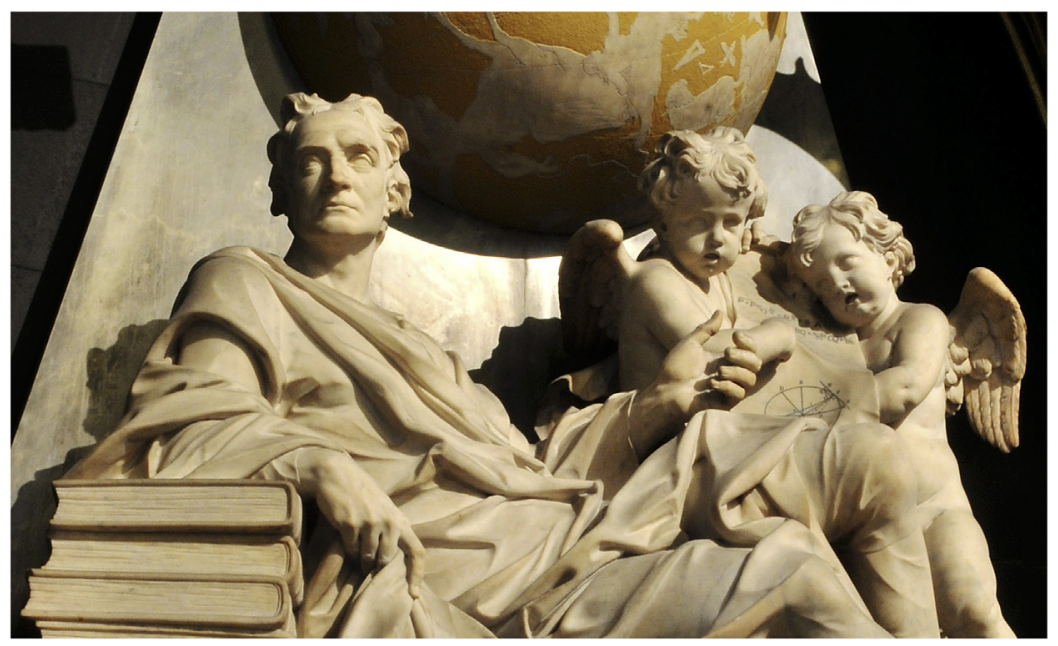

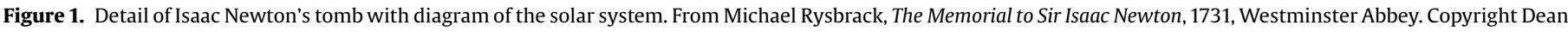
and Chapter of Westminster.

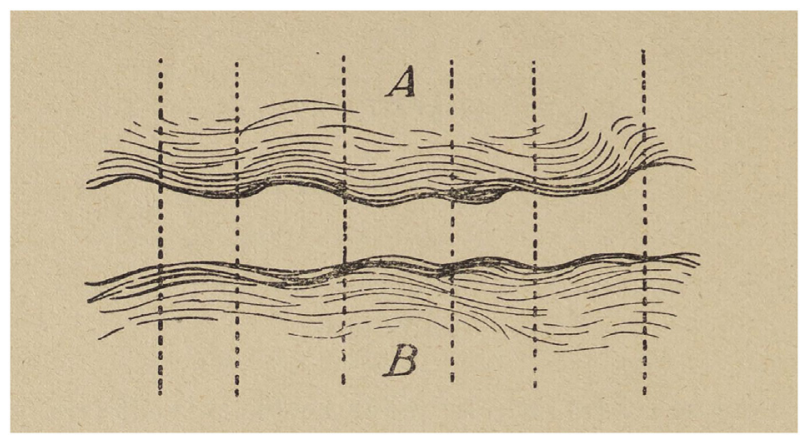

Figure 2. Ferdinand de Saussure's diagram of the connections between thought and sound. The horizontal wavy lines labeled A represent the "indefinite plane of confused ideas," and those labeled B represent the "equally indeterminate plane of sounds." The vertical dotted lines represent a how these two planes are brought into connection by language. From Cours de Linguistique Générale (Paris: Payot, 1931), 156. Courtesy of the Bibliothèque Nationale de France.

dotted lines connecting thought to sound (Figure 2). ${ }^{3}$ Or it may embody a sequence of causally related events, as in the case of a Feynman diagram of elementary particle interactions. ${ }^{4}$ Fundamentally, a diagram is a mediating object. It expresses our understanding of how things work by speaking to the eye.

This special issue, the product of an interdisciplinary workshop organized at Stanford University in 2017, brings together detailed case studies illustrating a wide variety of diagrammatic practices in science and mathematics since antiquity. The case studies presented include: the long evolution of Euclidian diagrams in the ancient, medieval, and early modern worlds; eleventh-century Chinese mathematicians who used diagrams as proofs of the correctness of the algorithms they had created to solve algebraic equations; a seventeenth-century Sicilian painter who drew diagrams to visualize missing aspects of fossils disfigured by the ravages of time and circumstance; a nineteenth-century naturalist who sketched diagrams to explore whether evolutionary processes could account for observed patterns in living nature; and contemporary mathematicians who manipulate diagrams to discover hidden properties of different classes of algebraic objects.

\footnotetext{
${ }^{3}$ Ferdinand de Saussure, Cours de Linguistique Générale, 3rd ed. (Paris: Payot, 1931), 156.

4 See David Kaiser, Drawing Theories Apart: The Dispersion of Feynman Diagrams in Postwar Physics (Chicago: University of Chicago Press, 2005).
}

Vast distances-of time, geography, and discipline-separate the episodes. Yet a deep and subtle connection binds them together. Each of the case studies examines diagrammingcreating and using diagrams-as an epistemic practice. We examine diagrams not merely as displays of information, but as reasoning tools, as objects that are, to quote Reviel Netz in his study of ancient Greek diagrams, "good to think with." ${ }^{5}$ Scientific and mathematical diagrams, like mathematical symbolic notations, can function as constrained representation systems used as cognitive instruments, allowing users to think with them and so generate knowledge and understanding. We focus, in short, on diagrams that function as tools of reason.

Three aspects of diagramming are central to understanding the use of diagrams as reasoning tools. Although these aspects overlap and interrelate, considering them separately is helpful in distinguishing key elements of the function of scientific diagrams:

- Diagramming is a material practice. Diagrams are generally twodimensional inscriptions on a surface, such as a sheet of paper or a computer screen. This two-dimensional material form underlies and informs how they function as tools of reason.

- Diagramming is a dynamic practice. Diagrams can serve as more than static images from which to extract information. Diagrams can be mentally manipulated to generate, explore, and test hypotheses. This manipulability is central to their ability to generate knowledge.

- Diagramming is a social and cognitive practice. Diagrams are used by particular communities of practice. They depend upon and exploit the users' cognitive capacities and learned competencies. By reproducing and sharing diagrams, users collectively constitute their own inter-subjective practices of representation that enable and constrain the use of diagrams as reasoning tools.

We begin our exploration of the use of diagrams as reasoning tools by briefly situating our approach to this special issue in the context of other scholarly explorations of scientific and mathematical diagrams. Subsequently, we offer a brief account of some uses of diagrams in DNA research to provide a concrete example from which to expand our discussion of diagrams as tools of reason, and the ways in which the material, dynamic, and social and cognitive aspects of diagramming contribute to its function as an epistemic practice. We discuss how

\footnotetext{
5 Reviel Netz, The Shaping of Deduction in Greek Mathematics: A Cognitive History (Cambridge: Cambridge University Press, 1999), 35.
} 
DNA diagrams became tools to reason about the structure of DNA. In particular, scientific practices involved in diagramming DNA embody the characteristics of materiality, dynamicity, and embeddedness in a social and cognitive context that we have identified as central to the function of diagrams as reasoning tools, making this famous historical episode an exemplary case study.

This brief meditation on diagramming DNA is a jumping off point for the broader themes of the special issue. It sets the stage for the other contributions. Each of them illuminates a range of diagrammatic practices, past and present, and helps us to better understand the role of diagrams as tools of reason. We focus especially on how each contribution contributes to the three essential features described above regarding the material, dynamic, and social and cognitive aspects of diagramming scientific and mathematical concepts.

\section{Diagrams as Things, Diagramming as a Practice}

Scientific and mathematical diagrams are multifarious. They define a vast landscape of knowledge and visual expression in many different cultures. No single discipline can lay claim to the diagram. As a result, they have been viewed through more than one disciplinary lensespecially art history and the more interdisciplinary field of visual studies, history and philosophy of science, and the cognitive sciencesand inspired different theoretical constructs devised to analyze them. It is not our purpose to review the literature here, but we can offer a few signposts that may assist the reader in navigating the landscape mapped by the contributions to this special issue.

Historians and philosophers of science have a longstanding interest in diagrams that has developed as part of a broader study of the relations between art and science. Brian Baigrie's edited volume on Picturing Knowledge (1996), Peter Galison and Caroline Jones's Picturing Science, Producing Art (1998), followed by David Kaiser's Drawing Theories Apart (2005), and Galison's coauthored study with Lorraine Daston, Objectivity (2007) have helped to stimulate interest in diagrams from this perspective. ${ }^{6}$ More than two decades of scholarship have made it increasingly clear how frequently natural philosophers, mathematicians, and physicians rethought the demonstrative power of images and vociferously debated with each other whether an image met the criteria of a "diagram." For some articulate proponents of this concept, such as the German astronomer Johannes Kepler, diagrammata meant geometric proof-which he contrasted to pictures, figures, or even hieroglyphs, all of them performing other visual functions that he found far less compelling. ${ }^{7}$ Diagrams are not only good to think with but also have epistemic power whose force and clarity is nonetheless mitigated by the heterogeneous landscape of visual practices-much vaster than Kepler's efforts to restrict the definition to his standards of proof-that constitute what diagramming means and does for scientists.

The emergence of this subject in the history and philosophy of science is deeply indebted to the discipline of art history, beginning with the pioneering work of figures such as Martin Kemp, whose research on Leonardo da Vinci has been a jumping off point for his broader meditations on the visual culture of knowledge. ${ }^{8}$ Most general

\footnotetext{
${ }^{6}$ Brian S. Baigrie, ed., Picturing Knowledge: Historical and Philosophical Problems Concerning the Use of Art in Science (Toronto: University of Toronto Press, 1996); Peter Galison and Caroline A. Jones, eds., Picturing Science, Producing Art (New York: Routledge, 1998); Kaiser, Drawing Theories Apart (ref. 4); Lorraine Daston and Peter Galison, Objectivity (New York: Zone, 2007).

${ }^{7}$ See Christoph Luthy and Alexis Smets, "Words, Lines, Diagrams, Images: Towards a History of Scientific Imagery," Early Science and Medicine 14 (2009): 398 439, esp. 434.

8 See most recently Martin Kemp, Structural Intuitions: Seeing Shapes in Art and Science (Charlottesville: University of Virginia Press, 2016), and his essays from Nature collected in Visualizations: The Nature Book of Art and Science (Oxford: Oxford University Press, 2010)
}

analyses of scientific diagrams have emerged from studies of visual representation. James Elkins's The Domain of Images (1999) is seminal in the study of visual representations. Elkins described his subject as "the domain of visual artifacts," observing that art historians had previously concentrated almost exclusively on fine art. He encouraged an expanded focus on the vast array of visual images beyond that limited sphere. ${ }^{9}$ Similarly, studies of images from a philosophical perspective, such as John Kulvicki's On Images (2006), have considered different kinds of images, including scientific ones. ${ }^{10}$

The visual turn in art history ultimately inspired more interdisciplinary work in visual studies, for example, Luc Pauwel's edited volume Visual Cultures of Science (2005), with an introduction on "The Role of Visual Representation in the Production of Scientific Reality." ${ }^{11}$ Not many years later, a Stanford literary scholar and an art historian, John Bender and Michael Marrinan, completed their foundational interdisciplinary study, The Culture of Diagram (2010). More recently, Horst Bredekamp's interdisciplinary research group completed a collaborative project on The Technical Image: A History of Styles in Scientific Imagery (2015). ${ }^{12}$ We might even consider Marzia Faietti and Gerhard Wolf's recent edited volume on The Power of Line (2016) as an example of the ways in which diagrammatic practices can become part of a study of artistic technique and geometric forms. ${ }^{13}$ All of these publications treat diagrams as a particular kind of visual representation. This visual orientation to diagramming has been enormously fruitful. However else they may be conceived, diagrams must be analyzed as images. Anyone working on scientific diagrams today is indebted to this important work on visual representation.

This considerable body of work has taken its place next to parallel literatures emerging primarily from two different contexts. The first is the interdisciplinary work in philosophy and cognitive sciences that has resulted in publications such as Alan Blackwell's edited volume on Thinking with Diagrams. ${ }^{14}$ This literature is closely connected to work on logic, artificial intelligence, and computer science. The second, also interdisciplinary, is focused on the use of diagrams to display complex information in ways accessible to nontechnical audiences. Founded by three pioneering books by Edward Tufte, ${ }^{15}$ this field has received increasing attention as diagrams migrate from the technical realm to major news outlets such as the New York Times as part of new experiments in communicating knowledge to broader publics in the form of complex visualizations. ${ }^{16}$ These two instances of the visual turn have stimulated

\footnotetext{
9 James Elkins, The Domain of Images (Ithaca: Cornell University Press, 2001), ix. 10 John V. Kulvicki, On Images (Oxford: Clarendon Press, 2006); John V. Kulvicki, "Knowing with Images: Medium and Message," Philosophy of Science 77, no. 2 (April 2010): 295-313.

11 Luc Pauwels, ed., Visual Cultures of Science: Rethinking Representational Practices in Knowledge Building and Science Communication (Hanover: Dartmouth College Press, 2005), vii.

${ }^{12}$ Horst Bredekamp, Vera Dünkel, and Birgit Schneider, eds., The Technical Image: A History of Styles in Scientific Imagery (Chicago: University of Chicago Press, 2015).

${ }^{13}$ Marzia Faietti and Gerhard Wolf, eds., The Power of Line (Munich: Hirmer Verlag, 2016).

14 Alan F. Blackwell, ed., Thinking with Diagrams (Dordrecht: Springer, 2001). For an analysis of diagrams from the perspective of formal logic, see Sun-Joo Shin, The Logical Status of Diagrams (Cambridge: Cambridge University Press, 1994); and SunJoo Shin, The Iconic Logic of Peirce's Graphs (Cambridge: The MIT Press, 2002).

${ }^{15}$ Edward R. Tufte, The Visual Display of Quantitative Information (Cheshire: Graphics Press, 1983); Envisioning Information (Cheshire: Graphics Press, 1990); and Visual Explanations: Images and Quantities, Evidence and Narrative (Cheshire: Graphics Press, 1997).

16 For two particularly effective examples of the power of such infographics, see Emily Badger, Clair Cain Miller, Adam Pearce, and Kevin Quealy, "Extensive Data Shows Punishing Reach of Racism for Black Boys," The New York Times, March 19, 2018, https://www.nytimes.com/interactive/2018/03/19/upshot/race-class-whiteand-black-men.html; and Nadja Popovich, Henry Fountain, and Adam Pearce, "We Charted Arctic Sea Ice for Nearly Every Day Since 1979. You'll See a Trend," The New York Times, September 22, 2017, https://www.nytimes.com/interactive/2017/09/22/
} climate/arctic-sea-ice-shrinking-trend-watch.html. 
great interest in human cognition and diagrammatic practices that ultimately fields such as history and philosophy of sciences and visual studies will want to account for.

In this special issue, however, we approach diagrams from a different orientation. Following a suggestion by Bender and Marrinan, we agree that it is productive to consider diagrams as "closer to being things than to being representations of things." 17 We consider diagrams as objects that exist in the world, in preference to seeing them as visual representations of aspects of the world. As Tim Ingold observes in his fascinating interdisciplinary history of lines, "human beings generate lines wherever they go." ${ }^{18}$ But if diagrams are things in the world, what kinds of things are they? They are concrete expressions of thought that facilitate comprehension and stimulate new patterns of thought. They are tools of reason.

Tools need to be understood by examining how and where they are used. We can learn many things about a lathe by examining it as it sits motionless on a workbench, but watching a lathe being used by an expert woodworker immeasurably enriches our understanding of the tool. The same principle applies to reasoning tools. We need to put them in their context to fully comprehend what they can do.

The contributions to this special issue therefore present detailed case studies of how diagramming functions in the context of particular scientific and mathematical practices. Following the example of other researchers who have attended closely to scientific practice, the contributors to this special issue have determined "to pay attention to scientific practices in meticulous detail and along multiple dimensions, including the material, tacit, and psycho-social ones." A focus on practice reduces the risk of an approach to science that is "too idealized and too disconnected from how science actually is performed in laboratories and other research settings."19 It grounds our historical and philosophical understanding of diagrams as things in the world.

Similar considerations have motivated an increasing focus on practice in the history and philosophy of mathematics. ${ }^{20}$ The central idea animating this movement is that mathematics, the most idealized and seemingly disembodied expression of thought, should be considered also as a human activity with a particular history rather than exclusively as a domain of eternal truths. The attention to mathematical practices has also led scholars to pursue detailed case studies and to attend as much to mathematicians in the act of conjecturing or discovering as they do to mathematicians in the act of proving theorems. Diagrams have proven to be a topic of special focus among scholars concerned with mathematical practices from antiquity to the present. ${ }^{21}$ These discipline-specific developments need to be considered in relation to a growing interest in the use of diagrams in fields such as medicine, natural history, astronomy, optics, physics, and engineering.

A special issue alone cannot claim to cover all these subjects; we have instead offered a diverse array of detailed case studies of diagrammatic practices, hoping that they will stimulate further work by other scholars. They do not aim at giving a general account of diagramming-which would inevitably be highly idealized-but seek to understand how diagramming functions in particular scenarios that define the reasons, the practices, and the possibilities of this kind of scientific visualization.

\section{Diagramming DNA: “A Jumble of Words and Diagrams”}

In this section, we offer an abbreviated account of uses of diagramming in two areas of DNA research-the determination of the double helical structure of DNA and the use of DNA topology to analyze DNA function.

\section{The Discovery of the Double Helix}

Although most accounts of James Watson and Francis Crick's work on the structure of DNA, which led to the discovery of its double-helix structure in 1953, focus on their investigations using three-dimensional models, diagramming was also central to their practice. $^{22}$ The blackboard in Crick's office at Cambridge was, according to his biographer Matt Ridley, "the focus of most discussions, accumulating a jumble of words and diagrams." The blackboard "continually changed its appearance, as many times during the day as new theories, speculations, and facts emerged." ${ }^{23}$ When the collaborators were not in Crick's office, they would make do with whatever was to hand. Crick scribbled diagrams on the blank back page of a manuscript he had been reading to explain to Watson how they might account for some of Rosalind Franklin's Xray crystallography findings. ${ }^{24}$ They communicated with each other and ultimately with a much broader public by diagramming.

By January 1953, Watson and Crick still had not reached a conclusion about DNA's structure. They knew that Linus Pauling was also working on the problem and were therefore initially devastated when they were shown a preprint in which Pauling and his collaborator Robert Corey proposed that DNA was structured as three helices spiraling off from a center sugar-phosphate backbone. $^{25}$ Watson and Crick greedily pored over the paper. After "less than a minute" reading the written summary and introduction, Watson turned to the diagrams in the manuscript, one of which is shown here as Figure 3. Studying them for several minutes led him to belief that Pauling and Corey's proposed structure could not possibly be right. ${ }^{26}$

\footnotetext{
17 Bender and Marrinan, The Culture of Diagram (ref. 1), 21.

18 Tim Ingold, Lines: A Brief History (London: Routledge, 2007), 1.

19 Léna Soler, Sjoerd Zwart, Michael Lynch, and Vincent Israel-Jost, "Introduction”, in Science After the Practice Turn in the Philosophy, History, and Social Studies of Science, ed. Léna Soler, Sjoerd Zwart, Michael Lynch, and Vincent Israel-Jost, 1-43 (New York: Routledge, 2014), on 1.

${ }^{20}$ A seminal publication in this tradition is Paolo Mancosu, ed., The Philosophy of Mathematical Practice (Oxford: Oxford University Press, 2008).

21 The first four chapters of Mancosu, ed., The Philosophy of Mathematical Practice (ref. 20) are dedicated to the study of mathematical diagrams. These include a specialist article by Marcus Giaquinto, which addresses issues of visual cognition and the famous "The Euclidean Diagram (1995)" by Kenneth Manders, which circulated widely as a manuscript before being published; the other two are more introductory contributions by the same authors. See also Marcus Giaquinto, Visual Thinking in Mathematics: An Epistemological Study (Oxford: Oxford University Press, 2007); and for a survey see Marcus Giaquinto, "The Epistemology of Visual Thinking in Mathematics," The Stanford Encyclopedia of Philosophy (Winter 2016 Edition), ed. Edward N. Zalta, https://plato.stanford.edu/archives/win2016/entries/epistemology-visual-thinking/.
}

\footnotetext{
22 Although we have focused this account on the diagrammatic practices of Watson and Crick, we are well aware that many others contributed substantially to the discovery that DNA is structured as a double helix. Rosalind Franklin's X-ray crystallography studies were also central to the discovery, for only one example. See, for instance, Lynne Osman Elkin, "Rosalind Franklin and the Double Helix," Physics Today 56, no. 3 (2003): 42-48.

${ }^{23}$ Matt Ridley, Francis Crick: Discoverer of the Genetic Code (New York: Harper Perennial, 2009), 102.

24 James D. Watson, The Double Helix: A Personal Account of the Discovery of the Structure of DNA (New York: Touchstone; 2001), 77. A number of Crick's early DNA diagrams can be viewed in the Francis Crick papers, held at the Wellcome Library in London. Some of this material has been digitized and is available online. Several DNA diagrams can be seen at "The Francis Crick Papers: Notes and Drafts/Notes and Drafts 1950-1955/“DNA”,” accessed March 17, 2018, https://profiles.nlm.nih.gov/ ps/retrieve/Series/10382.

${ }^{25}$ The paper was eventually published as Linus Pauling and Robert B. Corey, "A Proposed Structure for the Nucleic Acids," Proceedings of the National Academy of Sciences 39, no. 2 (1953): 84-97.

26 Watson, The Double Helix (ref. 24), 160.
} 


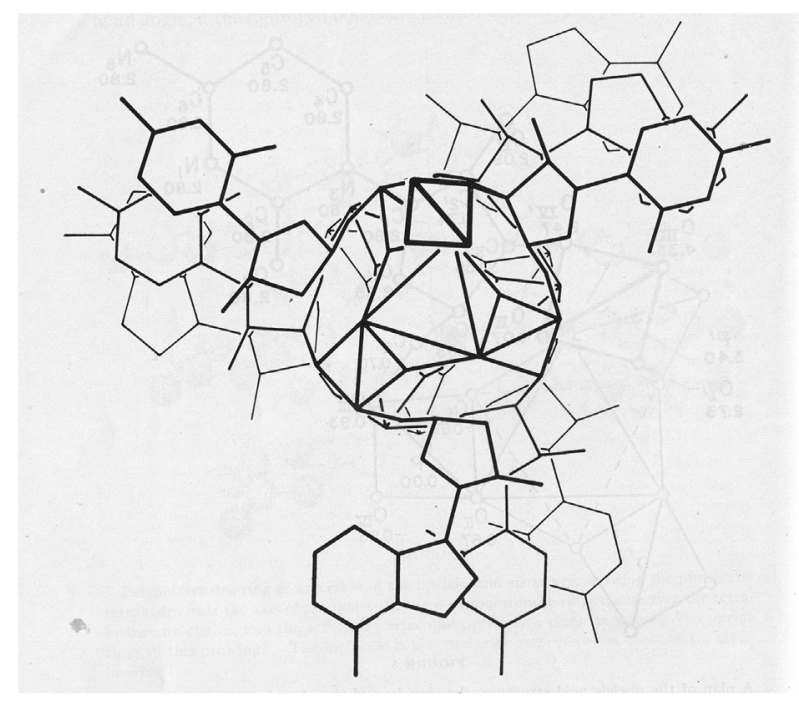

Figure 3. Linus Pauling's and Robert Corey's diagram of their hypothesized structure of DNA, with three helices spiraling off from a central sugar-phosphate backbone. From "A Proposed Structure for the Nucleic Acids," Proceedings of the National Academy of Sciences 39, no. 2 (1953): 84-97, on 92. From the Ava Helen and Linus Pauling Papers, OSU Libraries Special Collections \& Archives Research Center.

Convinced that Pauling and Corey would soon realize their error and resume their search for the correct structure, Watson and Crick redoubled their own efforts. They soon made an important breakthrough, leading them to conclude that DNA was structured as a double helix surrounding a sugar-phosphate backbone. They announced their findings publicly in the April 1953 issue of the journal Nature, opening this important paper by summarizing the problems with the Pauling and Corey (and another similar) structure. Watson and Crick then boldly proclaimed: "We wish to put forward a radically different structure for the salt of deoxyribose nucleic acid. This structure has two helical chains each coiled around the same axis (see diagram)." 27 This simple phrase invited readers to look at an image that precisely captured what they described in contrast to Pauling and Corey's diagram. It subsequently became one of the most iconic scientific diagrams of any age.

As soon as Watson and Crick started preparing their publication to announce their discovery, they realized that a diagram depicting the structure was essential to convey their proposal. Neither scientist was a gifted draughtsman, but Crick's wife Odile Crick was an artist (although she painted mostly nudes). They asked her to draw the diagram, and she agreed. Francis drew a preliminary diagram for Odile to work from (Figure 4). ${ }^{28}$

The diagram Odile created for publication became the conceptual and rhetorical center of the paper. ${ }^{29}$ Her transformation of her husband's sketch is shown in Figure 5.

The caption to the diagram reads: "The figure is purely diagrammatic. The two ribbons symbolize the two phosphatesugar chains, and the horizontal rods the pairs of bases holding the chains together. The vertical line marks the fibre axis."

What did it mean to be "purely diagrammatic" when representing DNA? The horizontal bars represent hydrogen bonds between pairs of bases, adenine always binding to thymine and cytosine always binding to guanine. As Watson and Crick noted, the diagram thus explains the

\footnotetext{
27 John D. Watson and Francis H. C. Crick, "A Structure for Deoxyribose Nucleic Acid," Nature 171 (April 25, 1953): 737-38, on 737.

28 Box number 69, Folder number PP/CRI/H/1/16, Identifier: SCBBWB, Francis Harry Compton Crick Papers, Wellcome Library for the History and Understanding of Medicine.

29 Watson and Crick, “A Structure for Deoxyribose Nucleic Acid” (ref. 27), 737.
}

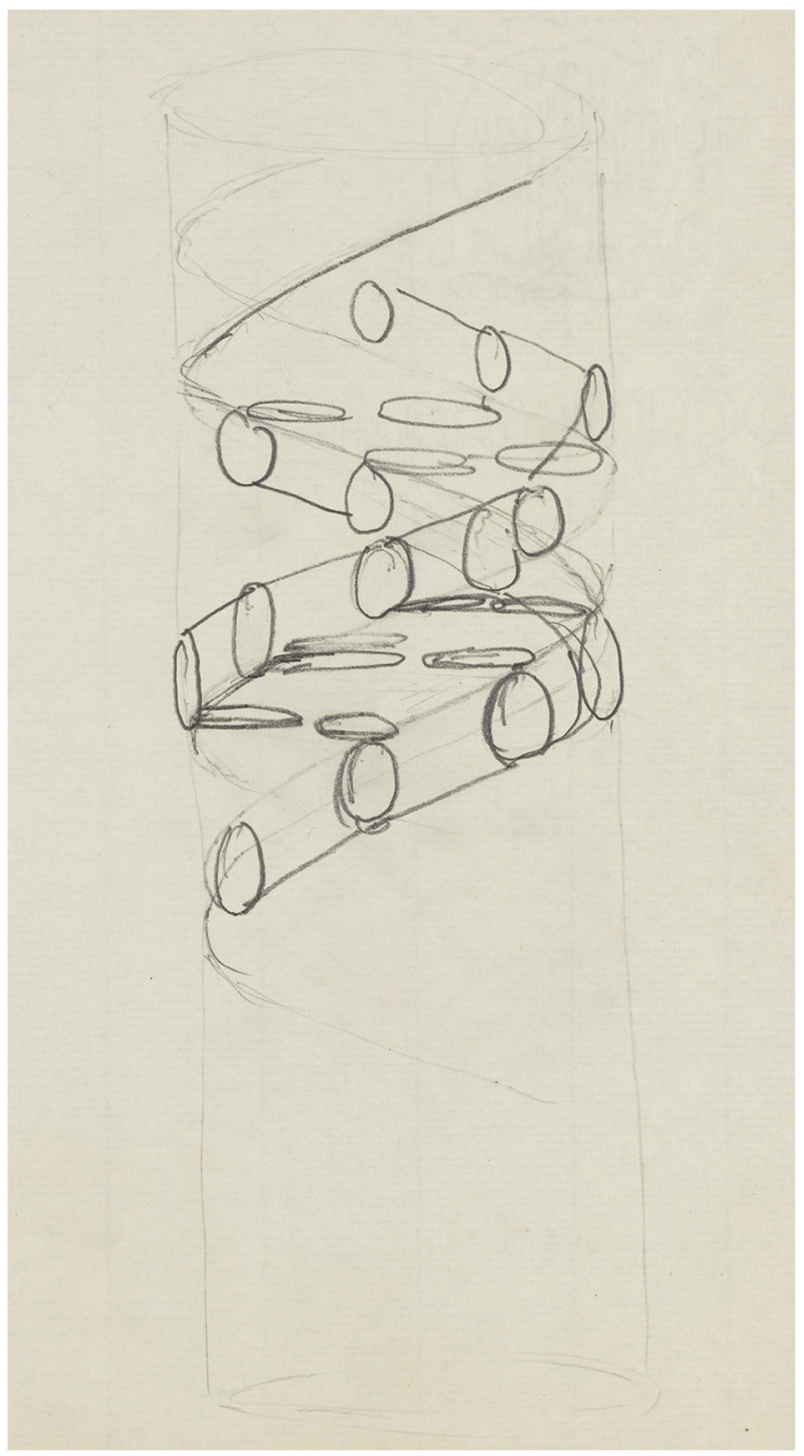

Figure 4. Francis Crick's preliminary DNA diagram, prepared for Odile Crick's use in creating the diagram for inclusion in the Nature paper announcing the discovery of the double helix. This image comes from Wellcome Images, a website operated by Wellcome Trust, a global charitable foundation based in the United Kingdom.

otherwise puzzling and previously unexplained observation that DNA always contains the same quantities of adenine and thymine, and of guanine and cytosine. The diagram also includes two arrows showing that one helix spirals up and to the right, and the other spirals down and to the left. Thus, "it follows that if the sequence of bases on one chain is given, then the sequence on the other chain is automatically determined." This, as the authors coyly observed, "immediately suggests a possible copying mechanism for the genetic material."30

Watson and Crick clearly considered the Nature diagram to be of great heuristic value. At the first public presentation of the discovery of the structure of DNA at a 1953 symposium at the Cold Spring Harbor Laboratory, Watson used the diagram to explicate the structure (see Figure 6). They included its exact facsimile in both of their other 1953 papers on DNA. ${ }^{31}$ Through replication, this

\footnotetext{
30 Watson and Crick, "A Structure for Deoxyribose Nucleic Acid" (ref. 27), 737.

31 James D. Watson and Francis H. C. Crick, "Genetical Implications of the Structure of Deoxyribonucleic Acid," Nature 171 (May 30, 1953): 964-67, on 965; "The Structure of DNA," Cold Spring Harbor Symposia on Quantitative Biology 18 (1953):
} $123-31$, on 125 
singular experiment in how to get an image of a structure right eventually became the diagram of DNA.

Today we are so seduced by the beauty, simplicity, and explanatory power of Watson and Crick's proposed structure that it comes as a surprise to learn that the initial response to their proposal was, as Robert Olby has put it, "lukewarm." ${ }^{32}$ One reason was that most DNA researchers were biochemists and physical chemists whose funding and institutional affiliations were chiefly medical. The primary interests of these scientists and their funders were the sources of DNA mutations and the details of protein synthesis. ${ }^{33}$ It was not until some years later that it became clear that the questions Watson and Crick were asking were even relevant to those concerns.

More substantive was the "unwinding problem": how does a long molecule with a double helical structure unwind so that the individual strands can be copied? Watson and Crick understood that "the difficulty is a topological one," ${ }^{34}$ but they had not developed the mathematical expertise that would have allowed them even to approach it seriously. They could only acknowledge that the problem was "formidable." ${ }^{35}$ Watson and Crick lamented that "it is difficult at the moment to see how these processes occur without everything getting tangled." 36 They had yet to solve a problem that both their explanation and their diagram raised.

\section{DNA Topology}

For some years thereafter, little fundamental progress was made on the unwinding problem. Although electron microscopy and X-ray crystallography enabled further advances on DNA structure, the processing of DNA required for such techniques to be used meant that they were able to provide little direct evidence for the shape of long chains of DNA in vivo. ${ }^{37}$

In 1962, at a meeting at which biologists were asked to present on new problems that might lend themselves to mathematization, Max Delbrück proposed that the knotting and entanglement of long chain organic molecules, including nucleic acids, were a good candidate. He offered his ideas "with considerable diffidence, feeling very uncertain whether the mathematical idealizations we introduce are physically appropriate and mathematically elegant, or even consistent." 38 Since then, scientists have continued down the path Delbrück mapped by developing topological techniques and applying them to these questions, thus giving rise to the field of DNA topology. ${ }^{39}$

One branch of topology that has been particularly fruitful in this respect is knot theory. ${ }^{40}$ Watson and Crick's double helix model can be approximated by a single string going through the axis of a double helix. This simplification allows us to model DNA as a string that can form physical knots. Knot theory allows us to study the

\footnotetext{
32 Robert Olby, “Quiet Debut for the Double Helix," Nature 421 (January 23, 2003): $402-5$, on 402.

33 Olby, "Quiet Debut" (ref. 32), 402.

34 Watson and Crick, "The Structure of DNA" (ref. 31), 128.

35 Watson and Crick, "The Structure of DNA" (ref. 31), 129.

36 Watson and Crick, "Genetical Implications" (ref. 31), 966.

37 De Witt Sumners, "Lifting the Curtain: Using Topology to Probe the Hidden Action of Enzymes," Notices of the American Mathematical Society 42, no. 5 (1995): 528-37, on 528.

${ }^{38}$ Max Delbrück, "Knotting Problems in Biology," Proceedings of Symposia in Applied Mathematics 14 (1962): 55-63, on 55.

39 See, for example, Andrew D. Bates and Anthony Maxwell, DNA Topology (Oxford: Oxford University Press, 2005); Steven A. Wasserman and Nicholas R. Cozzarelli, "Biochemical Topology: Applications to DNA Recombination and Replication," Science 232 (1986): 951-60; Sumners, "Lifting the Curtain" (ref. 37); and Dorothy Buck and Erica Flapan, "A Topological Characterization of Knots and Links Arising from Site-specific Recombination," Journal of Physics A: Mathematical and Theoretical 40 (2007): 12377-395.

40 See Sumners, "Lifting the Curtain" (ref. 37).
}

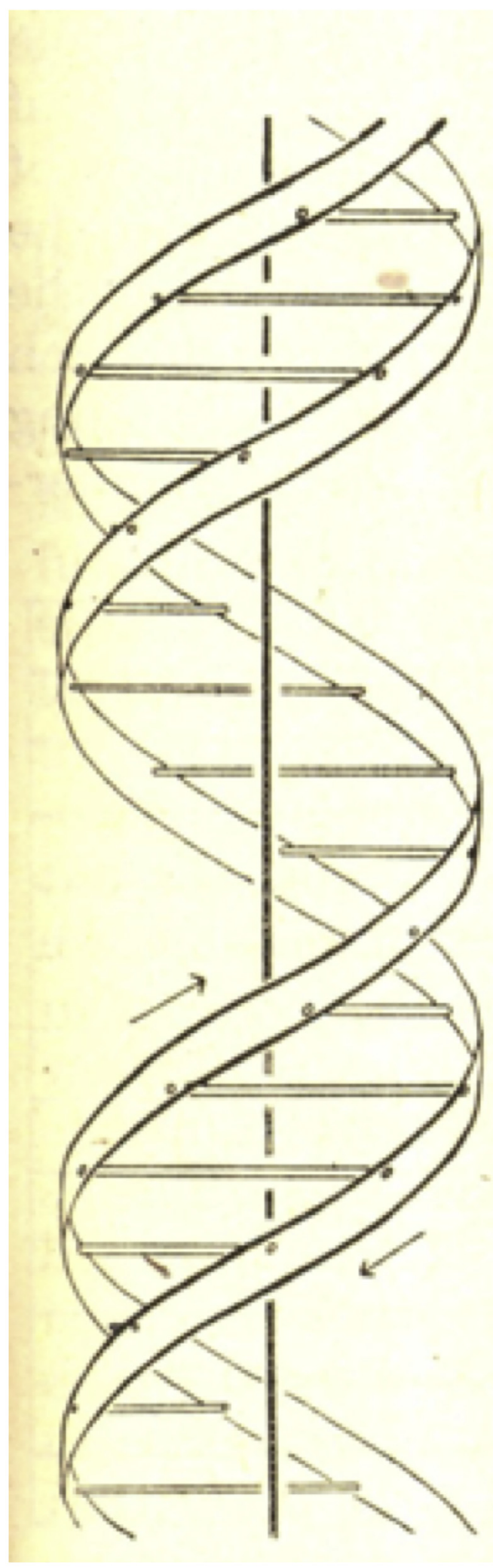

Figure 5. DNA diagram from James Watson's and Francis Crick's Nature paper announcing the discovery of the double helix. The two ribbons spiraling in opposite directions depict the sugar-phosphate chains, the horizontal lines depict the complementary base pairs joining the chains together, and the vertical line depicts the fiber backbone. Reprinted by permission from Macmillan Publishers Ltd: Nature (James D. Watson and Francis H. C. Crick, "A Structure for Deoxyribose Nucleic Acid," Nature 171 (April 25, 1953): 737-38, at 737), copyright 1953. Image courtesy of the Department of Special Collections, Stanford University Library. 


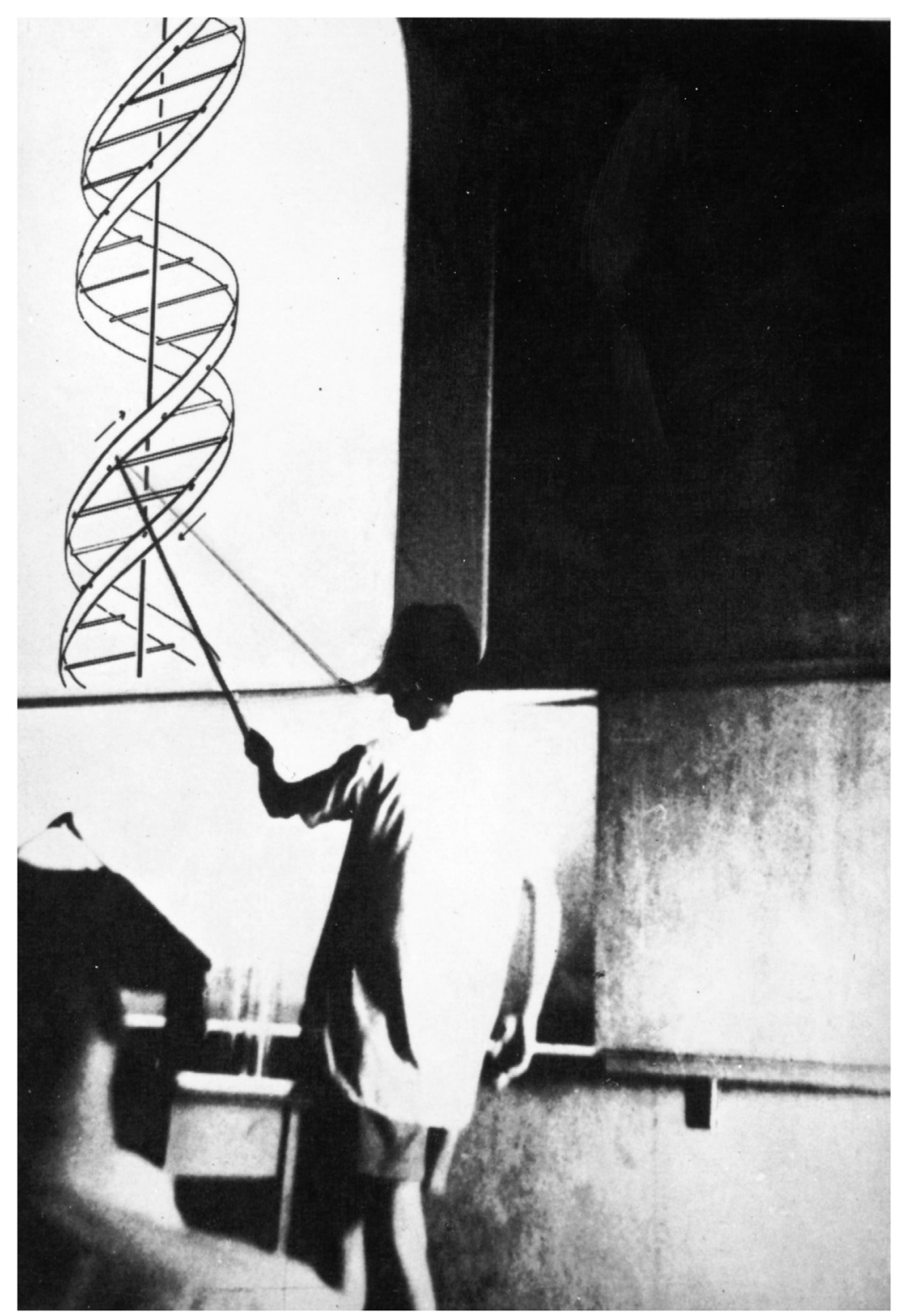

Figure 6. James Watson using the diagram from his and Francis Crick's Nature paper to explicate the structure of DNA at the first public presentation of Watson's and Crick's proposed structure at a 1953 symposium at the Cold Spring Harbor Laboratory. Courtesy of the Cold Spring Harbor Laboratory Archives.

properties of physical knots by abstracting them into mathematical knots, smooth closed simple curves embedded in three-dimensional space. The specific geometric shape of a knot is not relevant for the knot theorist; only the way it is knotted is mathematically relevant. Any two knots are of the same mathematical type if one can be turned into the other by continuously deforming it, without cutting it and re-gluing the ends. Knot theorists can investigate the properties of mathematical knots using knot diagrams, twodimensional projections of knots. As two-dimensional inscriptions, knot diagrams are easier to work with than three-dimensional knots, and, if manipulated according to rigorously defined rules, can generate valid mathematical results about the knots they represent. $^{41}$
To understand the application of knot theory to DNA structure, consider Figure $7{ }^{42}$ Figure 7 a shows a picture of a physical knot of DNA taken using an electron microscope. Figure $7 b-d$ render the knot diagrammatically, progressively showing how, by manipulating the knot's diagram, we can see that the apparently complicated physical knot is actually a mathematically simple trefoil knot. Thus, knot diagrams allow us to see properties of physical DNA knots that might not be apparent from, or might even be obscured by, photographic representations. By drawing a corresponding diagram, we simplify the representation by depicting only what is mathematically relevant. ${ }^{43}$

The simplification performed by the diagram may be helpful to researchers in many ways. A complex shape that appears thoroughly entangled in a photograph might turn out not to be

\footnotetext{
41 A fundamental theorem of knot theory-the Reidemeister theorem-holds that all diagrams representing the same knot can be shown to be equivalent by performing a series of three local moves: the Reideimeister moves. See Colin C. Adams, The Knot Book (New York: W. H. Freemand and Company, 1994), for an accessible introduction to knot theory.
}

\footnotetext{
42 Wasserman and Cozzarelli, "Biochemical Topology" (ref. 39), 952.

43 See Silvia De Toffoli and Valeria Giardino, "Forms and Roles of Diagrams in Knot Theory," Erkenntnis 79, no. 4 (2014): 829-42, for an epistemological analysis of knot
} diagrams. 


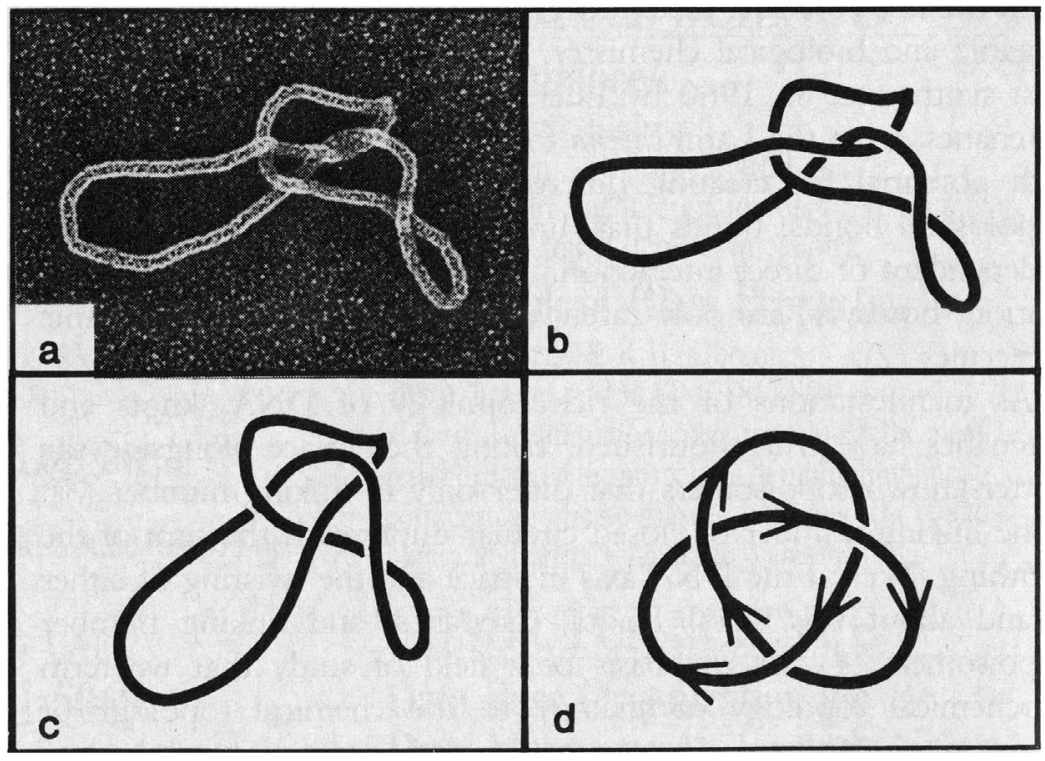

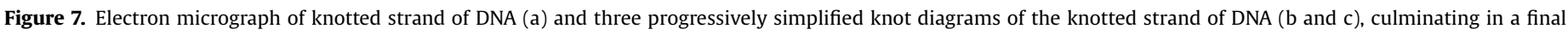

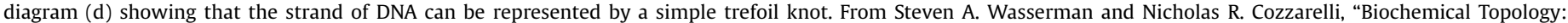
Applications to DNA Recombination and Replication," Science 232 (1986): 951-60, 952. Reprinted with permission from AAAS.

knotted at all, or to be knotted in a much simpler way than first appears. This also enables researchers to gain a better purchase on what kinds of topological deformations a strand of DNA might undergo. More generally, it has been claimed that "[t]opology affects virtually every nucleic acid process that requires the double helix to be opened or moved within the cell" and that "[t]opoisomerases, the enzymes that regulate the topological structure of DNA, play critical roles in fundamental cellular processes, including replication, transcription, recombination, and mitosis." ${ }^{44}$ Thus, diagramming DNA encouraged new ways of thinking about a broad array of genetic structures with the assistance of mathematical reasoning.

\section{What Kind of Tool Is a DNA Diagram?}

The foregoing excursus on the history of DNA research provides us with a concrete foundation from which we can begin to explore the attributes that diagrams used as reasoning tools tend to share, which we briefly identified at the beginning of this introduction.

\section{DNA Diagramming as a Material Practice}

Diagrams generally take the form of two-dimensional inscriptions on a surface such as paper or a computer screen. Watson and Crick's published diagram of the DNA double helix (Figure 5) is a two-dimensional projection of a three-dimensional shape. This material instantiation of the DNA diagram as a two-dimensional inscription is fundamental.

Watson and Crick also modeled DNA in three dimensions, using wires and balls (see Figure 8). This technique was helpful in visualizing aspects of the DNA structure, such as the angles at which the bases bond and the spatial relations of the bases to the sugar-phosphate backbone. However, it is much easier to infer the

\footnotetext{
44 Joseph E. Deweese, Michael A. Osheroff, and Neil Osheroff, "DNA Topology and Topoisomerases: Teaching a 'Knotty' Subject," Biochemistry and Molecular Biology Education 37, no. 1 (2009): 2-10, on 3 (citations omitted).
}

likely copying mechanism from an examination of the twodimensional diagram than from a three-dimensional model. ${ }^{45}$

On the other hand, Watson and Crick also described fundamental aspects of their proposed structure using text. This allowed them to provide the reader with a great deal of detail on bonding distances and angles not represented in the diagram. Nonetheless, the two-dimensional diagram offers a more immediate sense of a synoptic understanding of the structure. This contribution of the diagram to an understanding of the basics of DNA's structure is evidenced by Watson using it in his initial presentation of the structure at the symposium held at the Cold Spring Harbor Laboratory (see Figure 6) and Watson and Crick's inclusion of the original Nature diagram in so many of their subsequent papers.

Knot diagrams, too, are two-dimensional material inscriptions representing three-dimensional knots. Although knot diagrams can also be represented by a sequence of numbers, ${ }^{46}$ it is thanks to their two-dimensional layout that we can immediately visualize them as curves in space. Moreover, their two-dimensionality enables us to perform manipulations which, as illustrated in Figure 7, allow us to visualize how a tangled, three-dimensional strand of DNA can be seen as an instance of a simple trefoil knot. These manipulations on knot diagrams (the Reidemeister moves and their combinations) are easily interpreted as corresponding to manipulations of a string in three-dimensional space but at the same time correspond to rigorous mathematical operations.

\footnotetext{
45 Models in science and mathematics take many forms (only some of which are physical), and the literature analyzing how they feature in scientific and mathematical practice is extensive. See, for example, Roman Frigg and Stephan Hartmann, "Models in Science," The Stanford Encyclopedia of Philosophy (Summer 2018 Edition), ed. Edward N. Zalta, https://plato.stanford.edu/entries/modelsscience/; Michael Weisberg, Simulation and Similarity: Using Models to Understand the World (Oxford: Oxford University Press, 2013); and Ronald Giere, "An AgentBased Conception of Models and Scientific Representation," Synthese 172, no. 2 (2010): 269-81. For a discussion of the special characteristics and functions of three-dimensional models, see Soraya de Chadarevian and Nick Hopwood, eds. Models: The Third Dimension in Science (Stanford: Stanford University Press, 2004). ${ }^{46}$ For example, knot diagrams can be "coded" with the Dowker notation. See Adams, The Knot Book (ref. 41), chapter 2.
} 


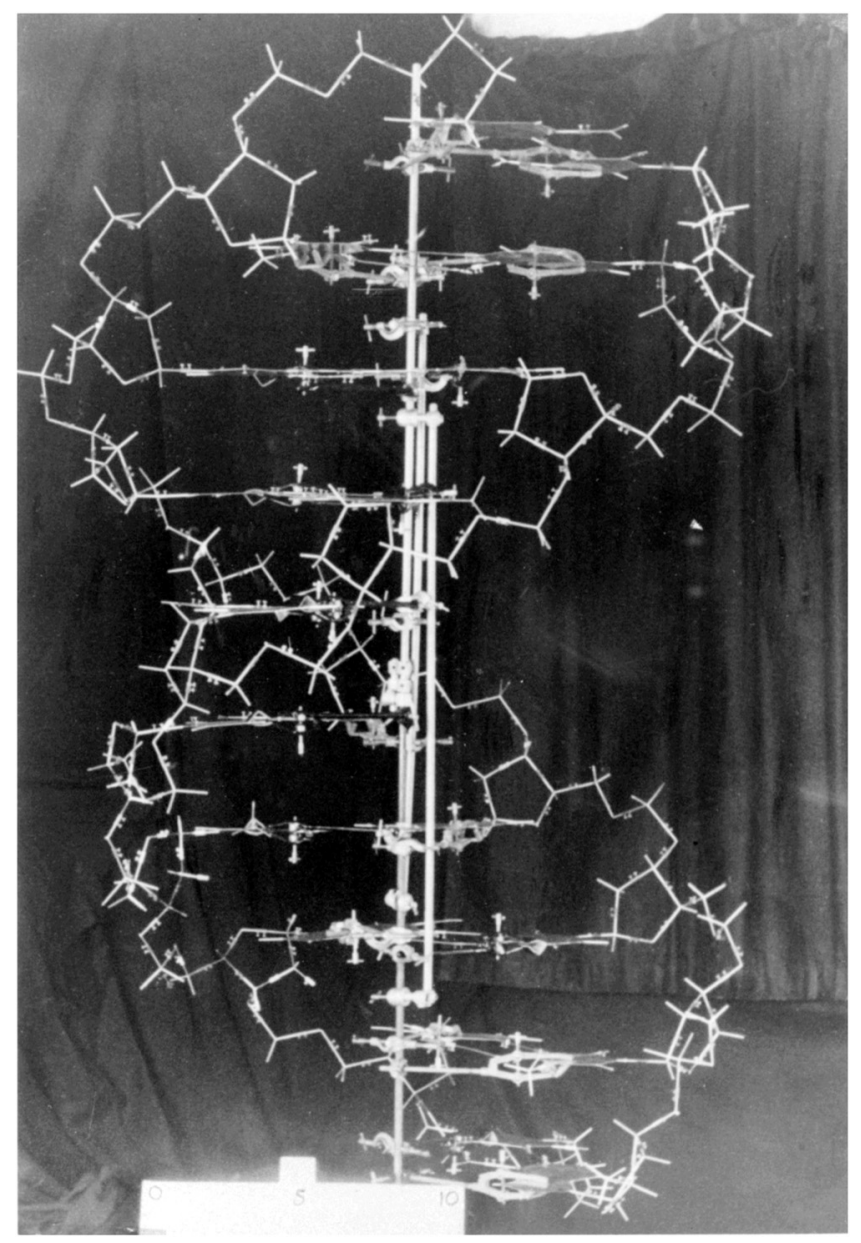

Figure 8. Watson and Crick's original three-dimensional demonstration model of the structure of DNA. Courtesy of the Cold Spring Harbor Laboratory Archives.

\section{DNA Diagramming as a Dynamic Practice}

Some visual representations are static displays of information: we derive information from them by reading it off of them. Such static displays can be useful devices for quick storage and retrieval of information, but our primary interest in this special issue is in diagrams that users interact with dynamically. Silvia De Toffoli and Valeria Giardino have proposed the term "manipulative imagination" to capture how users of knot diagrams mentally work with, reshape, and otherwise transform diagrams in order to answer questions and explore hypotheses. ${ }^{47}$ Their idea that one can gain knowledge from a diagram by performing manipulations on it applies as well to a variety of other diagrams.

In the case of knot diagrams, as well as diagrams used in other mathematical domains, these manipulations take the form of rigorously defined operations leading to verifiably valid results. ${ }^{48}$ In other areas, including many of the sciences, diagrammatic manipulations may not follow strict rules or generate results that can be conclusively validated, but they nonetheless support the development and testing of hypotheses about phenomena, as well as understanding of the operation of processes and mechanisms.

\footnotetext{
47 De Toffoli and Giardino, "Forms and Roles of Diagrams" (ref. 43).

48 Regarding the specific operations that are allowed on knot diagrams, see De Toffoli and Giardino, "Forms and Roles of Diagrams" (ref. 43). Regarding the specific operations used on commutative diagrams in homological algebra, see Silvia De Toffoli, “'Chasing' the Diagram-The Use of Visualizations in Algebraic Reasoning," The Review of Symbolic Logic 10, no. 1 (2017): 158-86.
}

We understand, for example, the mechanism by which Watson and Crick suggested that DNA might be copied through an act of manipulative imagination. Recall that the diagram from the Nature paper (Figure 5) includes arrows showing one helix coiling up and to the right and its complementary helix coiling down and to the left. These arrows encourage us to see beyond the literal image, forming a mental picture of the actions that will be performed. We imagine the two complementary strands of DNA unzipping. We then imagine each base in the resulting separate strands bonding with its complementary base, and we end with two complete strands of DNA identical with the one original strand. The diagram stimulates this subsequent portrait of nature in action.

Similar considerations apply in DNA topology. To realize that the physical strand of DNA (Figure 7a) can be represented by a simple trefoil knot diagram, we imagine the knot undergoing a series of transformations, aided by the sequence of diagrams (Figure $7 b-d$ ).

\section{DNA Diagramming as a Social and Cognitive Practice}

In order to make sense of actual scientific and mathematical practices, scientists and mathematicians are best understood not as disembodied reasoning machines, but as human actors participating in a communal and cognitive enterprise. This is relevant to the use of diagrams as tools in at least two respects. First, diagrams must be understood as they are used in a particular community of practice that is historically situated. Second, the people making up that community share learned competencies that tools of reason must take into account in order to speak to their intended audience. In other words, diagramming is a learned language. ${ }^{49}$

The two-dimensional material form of diagrams makes them particularly well suited for the communal production of knowledge. A diagram is usually easily reproduced and shared, formally and informally. A diagram can be scribbled on a piece of scrap paper in conversation, depicted on a slide during a lecture or conference presentation, shared publicly on the web, or published in a scientific article. Thus shared, the diagram becomes an intersubjective tool that can be used by different members of a community, simultaneously and asynchronously, locally and remotely, thus ultimately transcending the original community of practice in which it emerged.

The case of the double helix diagram nicely illustrates the ease with which diagrams can be shared and reproduced, fostering their utility as reasoning tools. The blackboard in Crick's office operated as a communal space for discussion by way of diagrams for an intimate scientific community. Watson and Crick used both diagrams and three-dimensional models in their own investigations of DNA, yet they could easily share their diagrams with other researchers through conference presentations and publications. In contrast, their three-dimensional models sat in their offices at Cambridge. Beyond the famous photograph shown in Figure 8 (which in any case, was not first published until much later), the model could not circulate to the same degree as the diagram.

A community of practice can, of course, be a hindrance to the acceptance or development of an idea as much as it can be a blessing. Consider the initially tepid reception of Watson and Crick's announcement of the double helix. There were, to be sure, theoretical concerns with their proposed structure, not least, the "unwinding problem." But the institutional and financial context of

\footnotetext{
49 Both interpretation and rules for correct use of diagrams are generally learned in a specific institutional context. In De Toffoli and Giardino, "Forms and Roles of Diagrams" (ref. 43), the authors write of "enhanced" manipulative imagination to stress the point that manipulative imagination is enhanced by training.
} 
the relevant community of practice was also critical. The primarily medical focus of that community militated against a serious engagement with Watson and Crick's proposal at the time they made it because it did not seem directly relevant to the community's work or to the objectives of their funders. Put a different way, the diagram was not legible by these criteria.

The development of the field of DNA topology is a particularly fine example of the importance of the cognitive aspect of diagrammatic practice. Few biologists in 1953 had even the most rudimentary understanding of mathematical topology. Crick and Delbrück had both begun their careers studying highly mathematical areas of physics, ${ }^{50}$ which may explain Crick's intuition that the unwinding problem was topological and Delbrück's suggestion that mathematical approaches to knots might be fruitful for the study of nucleic acid tangling. In order for DNA topology even to become viable as an area of study, scientists had to develop learned competencies in biochemistry and knot theory. Moreover, a sufficiently well-formed community had to develop that funding could be acquired, publications could be vetted, and junior researchers could be trained.

This excursus on diagramming DNA highlights the material, dynamic, and social and cognitive aspects of diagrammatic practices in the area of DNA research. They are all epistemic practices that make DNA diagrams powerful tools of reason. DNA diagrams have been and are being used not merely to represent knowledge, but as aids to generate knowledge. DNA researchers think-generating, testing, and sometimes even establishing the validity of hypotheses-by diagramming.

\section{Conclusion}

Diagramming is a central element of scientific and mathematical practice in a broad range of fields. Like any practice, diagramming is best understood by a careful investigation of its actual use in particular historical circumstances, and that is the method that the contributions to this special issue have employed. Yet, through their insights into the material, dynamic, and social and cognitive aspects of diagrams, they also lead us to certain general conclusions about how diagrams work in science and mathematics.

Of course, these preliminary observations about diagramming as an epistemic practice leave a great many questions about the use of diagrams in the setting of any particular practice still unanswered. The authors of the papers in this special issue use their case studies to ask some of these questions and to sketch the outlines of possible answers. They include: What does a particular diagram make visible, and what does it omit or obscure? Who is the intended audience? What happens when a diagram is used in ways that differ from the ones for which it was originally intended? Does the meaning of a diagram change when its use changes? How are diagrams affected by-and how do they in turn affect-the scientific and cultural contexts in which they are created and deployed? What makes a diagram effective as a reasoning tool? What makes a diagram ineffective, or even misleading? If diagrams generate knowledge, could the same knowledge be generated using a different modality? If so, what purpose is served by the use of diagrams?

\footnotetext{
50 Crick had started his $\mathrm{PhD}$ in physics with a supervisor who studied the mathematics of flow, viscosity and creep. Ridley, Francis Crick (ref. 23), 10-11. Delbrück earned his PhD in theoretical physics and did post-doctoral research on quantum mechanics with Niels Bohr and Wolfgang Pauli. "Max DelbrückBiographical," in Nobel Lectures, Physiology or Medicine (Amsterdam: Elsevier Publishing Company, 1972).
}

The eight papers in this special issue engage with the themes of this special issue. The first three essays deal with the evolution of diagrammatic practices between antiquity and the seventeenth century. Karine Chemla examines how an eleventh-century mathematical diagram interacts with the surrounding text and concludes that the diagram proves the validity of the algorithmic solution to the algebraic problem to which the diagram corresponds. She focuses in particular on how material aspects of the diagram, including its use of color and the placement of captions affects the diagram's use and meaning. Eunsoo Lee traces the evolution of editions of Euclid's Elements across a shift from a manuscript culture in which diagrams were visual auxiliaries in a text-centered presentation to a print culture in which diagramming emerged as a visual language. New readers with more practical needs for using diagrams were recruited for the Elements, and those readers were encouraged to construct the diagrams as they read. Paula Findlen studies how the seventeenth-century painter and naturalist Agostino Scilla used dotted lines and other diagrammatic techniques to develop and express visual hypotheses about the morphology of the living organisms whose fossil remains he painstakingly reconstructed. She also explores how Scilla collaborated with the engraver and draftsman Pietro Santi Bartoli to render his drawings into engravings for publication.

The second cluster of essays illuminates nineteenth-century diagrammatic practices in cosmology, engineering, and natural history. Jennifer Daly shows how the Romantic astronomer John Pringle Nichol and the artists and engravers David Scott and William Bell Scott worked together to create diagrammatic and pictorial representations embodying an unresolved tension between an ambition to convey knowledge extending beyond the realm of human perception and a recognition of humans' inevitably partial and imperfect epistemic purchase on the world. Norton Wise recounts how practical engineers around the turn of the nineteenth century who were concerned with keeping steam engines running efficiently created instruments that inscribed diagrams that could be read like a medical case report to diagnose the problem and suggest remedies. He then shows how later physicists reinterpreted and refigured those diagrams as tools to explore general properties of thermodynamic systems. Greg Priest traces how Charles Darwin used tree diagrams to give visual expression both to observed patterns in nature and to conjectural narratives of evolutionary history so that he could investigate the narratives' power to explain the patterns. He also explores how Darwin's diagrams call for, and reward, imaginative manipulations in which the reader follows the diagram down a prescribed path, then mentally rescales the diagram, and finally entirely reinterprets it to refer to new and different entities and phenomena.

The final section of the special issue explores the recent evolution of diagrammatic practices in mathematics. Valeria Giardino analyzes topological diagrams used by contemporary mathematicians and Gottlob Frege's Begriffsschrift (concept notation), which is a two-dimensional notation for logic, as examples of "cognitive tools"-human-designed material objects that enable, and shape, the way we think. She examines how users bring their manipulative imagination to the diagrams and uses the psychological concept of "affordances" to analyze diagrams in terms of the uses they support by human actors with characteristically human cognitive capacities. Jessica Carter analyzes contemporary mathematical practice, drawing on her interpretation of Charles Sanders Peirce's semiotics to suggest that certain diagrams can be understood as "faithful representations," because they support rigorous manipulations that allow them to connect different domains of mathematical inquiry diagrams. She concludes that these diagrams can generate "epistemic gains."

Almost six hundred years ago, Leon Battista Alberti defined the ideal drawing as "a precise uniform representation conceived in 
the mind." 51 Alberti's pictorial idiom is not necessarily our own; he innovated practices specific to the revival of Euclidean thought and its applications to painting in fifteenth-century Italy that have been subsequently used and transformed in other contexts. ${ }^{52}$ Yet he reminds us that science always makes the diagram. Diagrams do not make science, but diagram-makers give knowledge concrete visual expression that, as the case of the double helix reveals, can allow it to travel and ultimately transcend the original circumstances of its production.

\section{Acknowledgments}

We would first like to thank our contributors for making this project move swiftly and pleasurably to completion. This volume began as a February 2017 workshop held at the Stanford Humanities Center with the sponsorship of Suppes Center for the History and Philosophy of Science and the Departments of
History and Philosophy at Stanford University. Rosemary Rogers provided invaluable logistical support for the workshop. We would also like to thank the workshop commentators: John Bender, Michael Marrinan, Marco Panza, Jessica Riskin, and Rasmus Winther. Moreover, we thank the other participants in the workshop, including Michael Friedman, James Griesemer, Jemma Lorenat, Kenneth Manders, John Mumma, Reviel Netz, Thomas Ryckman, and John Sullivan. Last but hardly least, we have benefited from the energetic, skillful, and cordial support from the Co-Editors in Chief for this journal, Richard Bellon and Joseph D. Martin. For assistance with images, we thank the Department of Special Collections, Stanford University Library (especially Tim Noakes and Larry Scott), the Cold Spring Harbor Laboratory Archives (especially Stephanie Satalino), The Westminster Abbey (especially Christine Reynolds), the Oregon State University Libraries Special Collections \& Archives Research Center (especially Chris Petersen) and the Bibliothèque Nationale de France.

\footnotetext{
51 Leon Battista Alberti, On Painting, as quoted in Wolfgang Lefèvre, ed., Picturing Machines 1400-1700 (Cambridge: MIT Press, 2004), 175.

52 The classic study of this moment remains Michael Baxandall, Painting and Experience in Fifteenth-Century Italy (Oxford: Oxford University Press, 1972).
} 